\title{
Impedance pneumograph studies in left ventricular failure
}

\author{
A. R. T A N S E R \\ From King's College Hospital, Denmark Hill, London, S.E.5
}

Tidal volume can be measured by recording the changz in impedance of the thorax caused by breathing. Thus breathing can be recorded quantitatively from two electrodes placed on each side of the chest. The method is especially useful in breathless patients and studies of breathing patterns during sleep. A patient with a long circulation time due to left ventricular failure had periodic breathing both awake and asleep. When asleep the respiratory minute volume was considerably reduced, and there were long apnoeic periods. This was associated with a rise in mean right atrial pressure until the patient woke with an attack of paroxysmal dyspnoea. The right atrial pressure dropped to normal when the patient breathed more regularly. Anoxia probably caused the rise in right atrial pressure. Periodic breathing disappeared when the circulation time shortened after treatment of the heart failure. The possible mechanism of these changes is discussed.

Until recently it has been difficult to study breathing quantitatively without influencing its pattern by the method of recording. Face masks, mouthpieces, and constricting plethysmographs are all likely to alter the way a patient breathes, and are tolerated with difficulty by breathless patients. The impedance pneumograph (Pallett and Scopes, 1965) measures breathing quantitatively by recording the change in thoracic impedance to a high frequency current using surface electrodes. The method does not disturb the patient. Quantitative recordings of breathing can be made, even in breathless patients, both awake and asleep.

This method of recording breathing was used in a patient with left ventricular failure who complained of attacks of paroxysmal nocturnal dyspnoea. The right atrial pressure was recorded before and during an attack of dyspnoea, in order to establish the nature of the attack and so find possible means of prevention. As the patient's cardiac condition improved, there were changes in the pattern of breathing which were recorded.

\section{METHODS}

RECORDING RESPIRATION Breathing was recorded with an electrical impedance pneumograph (Pallett and Scopes, 1965) on one channel of a Sanborn 2-channel recorder. In this system, a $100 \mathrm{kc}$./ sec. alternating current (approximately $50 \mu \mathrm{A}, 0.25 \mathrm{~V}$ ) is passed through the chest by a pair of electrodes placed on each side of the chest near the mid-axillary line. The potential difference developed across the chest. measured at a second pair of electrodes, is amplified by a high frequency amplifier, and rectified and smoothed to give a direct voltage. This voltage is made equal to a reference voltage at the end of expiration. Inspiration increases the resistivity of the tissues, causing the direct voltage to exceed the reference voltage. This difference is amplified and displayed through the pen recorder, and is proportional to the inspired volume. The electrodes used were brass strips, $6.25 \times 1.25 \mathrm{~cm}$., with a $0.2 \mathrm{~cm}$. diameter stainless steel tube soldered longitudinally to the centre of the strip to make a ridge. These are similar to the electrodes described by Hamilton, Beard, and Kory (1965). The position of the electrodes is important (Baker, Geddes, and Hoff, 1966), and the best position in each patient is found by experiment. In this patient, the two electrodes were placed longitudinally on either side of the mid-axillary line with the lower poles at the level of the ziphisternum. They were secured with adhesive plaster. The system is calibrated at the start and finish of each period of observation with a low resistance spirometer recording through a potentiometer mounted on the pulley. The calibration is affected by the position of the patient, which must remain the same during recording. The change in impedance is related in a curvilinear way to the tidal volume (Fig. 1). With optimum placing of the electrodes this curve approximates to a straight line. In this patient the correlation was approximately $\mathrm{r}=0.97$. 


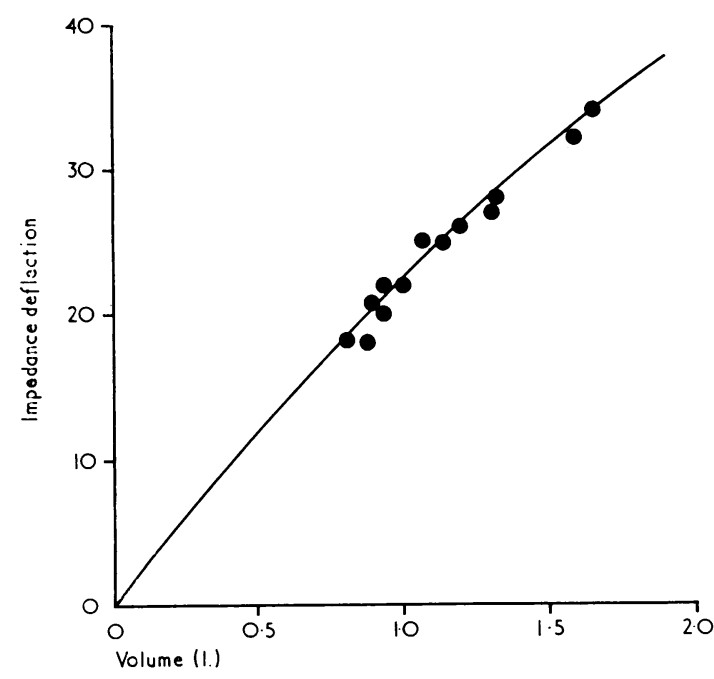

FIG. 1. The relation between change in volume and change in impedance. The impedance change is plotted as $\mathrm{mm}$. deflection on the recording paper.

RIGHT ATRIAL PRESSURE The integrated mean right atrial pressure was measured continuously through a no. 5 cardiac catheter filled with heparinized saline and connected to a Sanborn 268 B transducer.

END-TIDAL CARBON DIOXIDE TENSION This was measured with a respiratory mass spectrometer through a fine maranyl tube inserted through the nose into the pharynx. This was not found to cause any disturbance of the breathing pattern.

CIRCUlation TIME A fine polyethylene tube was passed through an arm vein into the axillary vein. Coomassie blue was injected rapidly, and detected at the ear with a Cambridge ear-lobe oximeter.

\section{CASE HISTORY}

Mr. A. F. aged 71 had attacks of paroxysmal nocturnal dyspnoea in 1966, which were treated with diuretics. He remained well until May 1966, when he became increasingly breathless on exertion and again had attacks of paroxysmal nocturnal dyspnoea. On admission to hospital his jugular venous pressure was normal, and there was no peripheral oedema. The heart was enlarged, blood pressure $180 / 100 \mathrm{~mm} . \mathrm{Hg}$, and there was a diastolic triple rhythm. An electrocardiogram showed left bundle-branch block. There was no abnormality in the central nervous system. He was treated with digoxin, diuretics, and a restricted salt diet. He had one attack of nocturnal dyspnoea in hospital but otherwise improved steadily. He became less breathless on exertion and the triple rhythm disappeared.

\section{RESULTS BEFORE TREATMENT}

PAROXYSMAL NOCTURNAL DYSPNOEA Tidal volume and mean right atrial pressure were recorded as the patient went to sleep, propped securely at an angle of $45^{\circ}$. The patient had gross periodic breathing (Fig. 2), which continued throughout the period of sleep. When awake, the respiratory minute volume was $14 \cdot 2$ litres. After 45 minutes of sleep this fell to 11.8 litres. During the second hour the respiratory excursions became smaller and less frequent, and the minute volume fell to 6.6 litres. The apnoeic interval between the bouts of ventilation increased from 5 to 30 seconds. The length of the total respiratory cycle also lengthened (Fig. 3).

During the first two hours the mean right atrial pressure rose steadily from $0 \mathrm{~cm}$. water to $+5 \mathrm{~cm}$. water. The patient then woke breathless. He sat up in bed but was given no treatment. Quantitative measurements of ventilation could not be made because of the change of position which affects the calibration of the pneumograph. However, the patient was observed to have increased ventilation for about 10 minutes, and his breathing became regular, without periodicity. The mean right atrial pressure fell to $0 \mathrm{~cm}$. water, and his dyspnoea quickly subsided. After 45 minutes he went to sleep again. Similar but less severe changes occurred in the respiration and venous pressure. The patient remained asleep without becoming breathless.

PERIODIC BREATHING WHILE AWAKE The following day the patient continued to have periodic breathing. End-tidal gas sampling showed a swing in carbon dioxide tension $\left(\mathrm{PCO}_{2}\right)$ between 27 and $40 \mathrm{~mm}$. $\mathrm{Hg}$ (Fig. 4). Mixed venous $\mathrm{PCO}_{2}$ by the re-breathing method was $47 \cdot 2 \mathrm{~mm}$. $\mathrm{Hg}$, and minute ventilation was 12.9 litres. Intravenous aminophylline, $200 \mathrm{mg}$., abolished periodic breathing for only 3 minutes. Oxygen had no effect.

CIRCULATION TIME The time from injection of the dye into the axillary vein until its appearance in the ear was 28.5 seconds (average of two readings).

\section{RESULTS AFTER TREATMENT}

RESPIRATION WHEN AWAKE There was no definite periodicity of breathing or end-tidal $\mathrm{PCO}_{2}$ (Fig. 4). The minute volume was $7 \cdot 3$ litres.

RESPIRATION DURING SLEEP When the patient was drowsy or lightly asleep, periodic breathing was observed. This persisted for about 10 minutes 


\section{After treatment. Becomes regular during sleep.}

FIG. 2. (Above) Periodic breathing as it occurred after one hour of sleep. The record reads from right to left. Inspiration upwards. Heavy vertical lines-5 seconds. (Below) After treatment. Periodic breathing at the start of sleep, becoming gradually even.

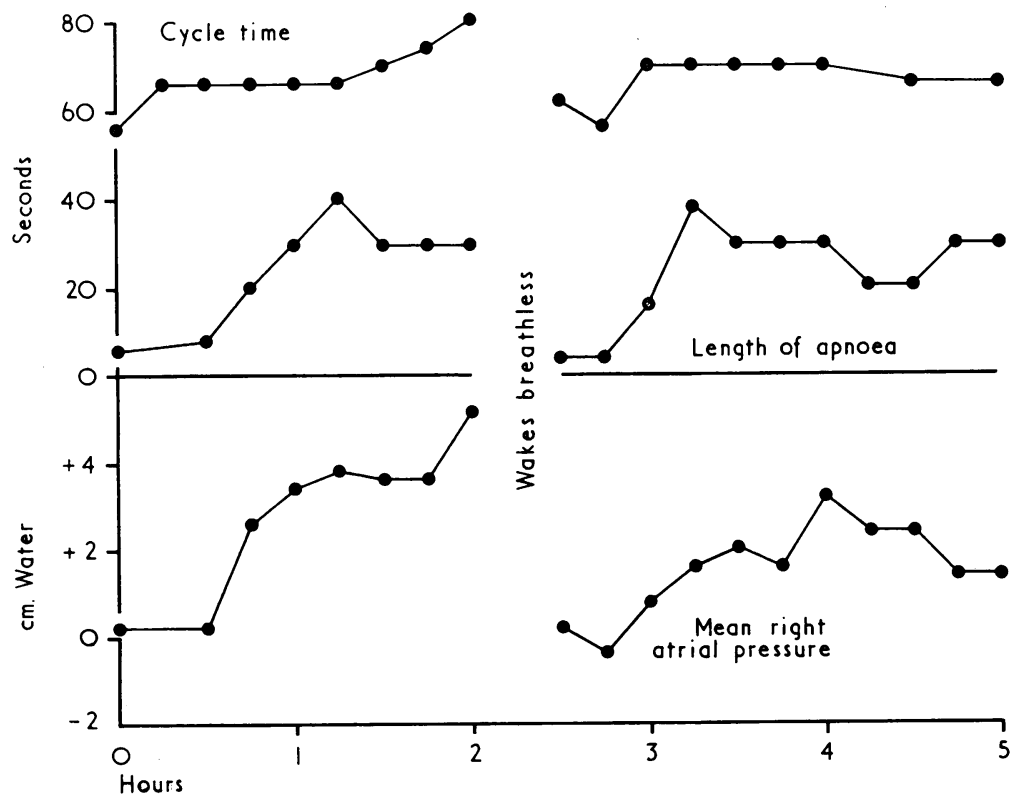

FIG. 3. Respiratory cycle length, length of apnoea, and mean right atrial pressure plotted against time before, leading up to, and after an attack of paroxysmal dyspnoea. 


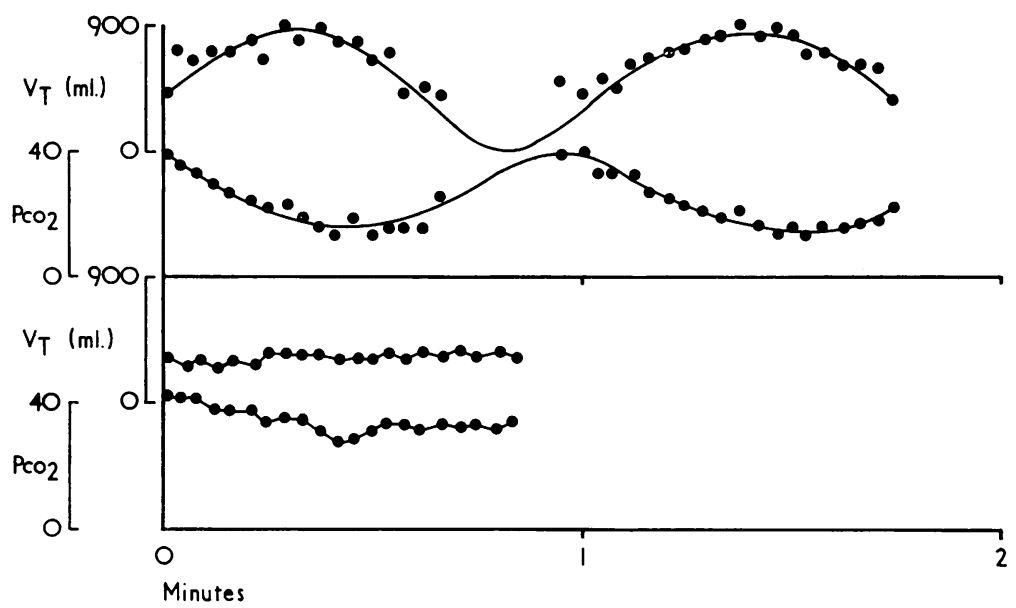

FIG. 4. (Above) End-tidal $\mathrm{PCO}_{2}$, in $\mathrm{mm}$. $\mathrm{Hg}$, and tidal volume during periodic breathing. (Below) After treatment. There is now no periodicity.

after the onset of sleep, and then gradually flattened out, with no change in cycle time, and became regular and even at 18 breaths a minute (Fig. 2). During the periodic breathing the minute volume was 9.36 litres, and during even breathing $5 \cdot 1$ litres.

CIRCUlation time The axillary vein to ear time was 16 seconds (average of three readings).

\section{DISCUSSION}

PERIODIC BREATHING This type of breathing may occur in healthy people during sleep (Broadbent, 1877 ; Haab, Ramel, and Fleisch, 1957). It also appears in many pathological conditions, especially in left-sided heart failure and in the presence of cerebral disease or injury. This type of respiration is often called Cheyne-Stokes breathing. Cheyne (1818), and later Stokes (1854), gave clear descriptions of periodic breathing, and Stokes specifically related it to heart disease. However, it would be surprising if such a striking symptom had not been noticed before. Hippocrates (circa 450 B.c.) described two cases occurring in fevers, possibly malaria. John Hunter (1794) gave an excellent description of a lady who lived in Norris Street, Haymarket, (who) fell into an apoplectic fit in which she was insensible respecting ideas; . . . I opened the temporal artery ... I observed that when she breathed freely the blood from the artery became red; and when her breathing was difficult, or when she hardly breathed at all, the blood became dark, and this alternated several times in the course of the bleeding; yet all this made but little alteration to the pulse'. It is possible that Hunter himself experienced periodic breathing in 1773 following his first myocardial infarct'the pain still continued and he found himself at times not breathing' (Home, 1794).

Some types of periodic breathing, especially in cardiac failure, are due to oscillation of the respiratory control system, associated with a prolonged circulation time. There is always a delay before changes in the gas tensions of the pulmonary capillary blood reach the respiratory centre(s) in the brain, but stabilizing factors such as the bicarbonate reserve, tissue $\mathrm{CO}_{2}$ stores, and mixing of blood in the left ventricle and great vessels normally tends to prevent oscillation. An experimental increase in the lung-to-brain circulation time causes periodic breathing (Guyton, Crowell, and Moore, 1956). Analogue computer analysis of periodic breathing (Milhorn and Guyton, 1965), using a mathematical model, suggested that the two most important factors in the stability (or instability) of the respiratory control system were the arterial circulation time and the excitability of the respiratory centre. The longer the arterial circulation time, and the more excitable the respiratory centre, the greater was the tendency to oscillation.

Before treatment this patient had a prolonged axillary vein-to-ear time, and so probably a prolonged lung-to-brain circulation time. He had periodic breathing both awake and asleep. After treatment the circulation time was decreased, and when he was awake there was no periodic breathing. The return of periodic breathing at the start of sleep was not due to any change in posture, as all recordings, awake and asleep, were carried out in the same position. When awake, external stimuli 
and conscious control may have prevented periodic breathing. Alternatively, a further lengthening of the circulation time may have occurred at the time of the sleep recording. The oscillation lasted $10 \mathrm{~min}$. and gradually became regular. If, at the start of sleep, conditions were just sufficiently unstable to allow periodic breathing to occur, a reduction in the circulation time, or decreased excitability of the respiratory centre, would theoretically abolish the oscillation. The respiratory centre is known to become less excitable during sleep (Bülow, 1963), and this probably explains the changes observed.

Patients with left-sided heart failure may become breathless at night because the blood volume increases as fluid is resorbed into the circulation (Perera and Berliner, 1943). In these circumstances the right atrial pressure rises, and the increased load in the left ventricle precipitates pulmonary oedema. This is not likely to have been the cause of this patient's dyspnoea. Although the right atrial pressure rose steadily before the attack of dyspnoea, it fell rapidly during the attack. Without drug treatment or evidence of spontaneous diuresis it is difficult to explain why the right atrial pressure should fall when the circulating blood volume remained increased. There is an alternative explanation. Anoxia causes increased pulmonary vascular resistance (Liljestrand, 1948) and may precipitate pulmonary oedema. In this patient during sleep there was a considerable reduction in minute volume, from 14.2 to 6.6 litres a minute, and apnoeic periods of 30 seconds. Arterial oxygen tension was not measured, but it is likely that significant anoxia (and thus pulmonary vasoconstriction) occurred. This would have been relieved by the return of normal ventilation when the patient woke, and would explain the observations described.
Oxygen did not abolish the periodic breathing when the patient was awake because he was not anoxic. However, it would have prevented anoxia occurring during sleep even with apnoeic periods of 30 seconds and the reduction in minute volume that occurred, and might have prevented this patient's attack of dyspnoea.

I wish to thank Dr. R. S. Bruce Pearson and Dr. P. Hugh-Jones for their helpful advice and criticism.

This study was supported by a grant from the King's College Hospital Research Fund.

\section{REFERENCES}

Baker, L. E., Geddes, L. A., and Hoff, H. E. (1966). A comparison of linear and non-linear characterizations of impedance spirometry data. Med. biol. Engng, 4, 371.

Broadbent, W. H. (1877). On Cheyne-Stokes' respiration in cerebral haemorrhage. Lancet, 1, 307.

Bülow, K. (1963). Respiration and wakefulness in man. Acta physiol. scand., 59, suppl. 209, p. 51.

Cheyne, J. (1818). A case of apoplexy in which the fleshy part of the heart was converted into fat. Dublin Hosp. Rep., 2, 216.

Guyton, A. C., Crowell, J. W., and Moore, J. W. (1956). Basic oscillating mechanism of Cheyne-Stokes breathing. Amer. J. Physiol., 187, 395.

Haab, P., Ramel, F., and Fleisch, A. (1957). La respiration périodique lors de l'assoupissement. J. Physiol. (Paris), 49, 190.

Hamilton, L. H., Beard, J. D., and Kory, R. C. (1965). Impedance measurement of tidal volume and ventilation. J. appl. Physiol., 20,565 .

Hippocrates (Circa 450 B.C.). Epidemics Book I, case 1. Epidemics Book III, case 15 .

Home, E. (1794). A short account of the author's life: Preface to $A$ Treatise on the Blood, Inflammation, and Gun-shot Wounds (J. Hunter), p. xlvi. Richardson, London.

Hunter, J. (1794). Ibid., p. 55.

Liljestrand, G. (1948). Regulation of pulmonary arterial blood pressure. Arch. intern. Med., 81, 162.

Milhorn, H. T., and Guyton, A. C. (1965). An analog computer analysis of Cheyne-Stokes breathing. J. appl. Physiol., 20, 328.

Pallett, J. E., and Scopes, J. W. (1965). Recording respirations in newborn babies by measuring impedance of the chest. Med. Electron. biol. Engng. 3, 161 .

Perera, G. A., and Berliner, R. W. (1943). The relation of postural hemodilution to paroxysma! dyspnea. J. clin. Invest., 22, 25.

Stokes, W. (1854). The Diseases of the Heart and the Aorta, p. 323. Hodges and Smith, Dublin. 